\title{
A Review of Pedicled Perforator Flaps for Reconstruction of the Soft Tissue Defects of the Leg and Foot
}

\author{
O-Wern Low ${ }^{1}$ Sandeep J. Sebastin ${ }^{1}$ Andre E. J. Cheah \\ ${ }^{1}$ Department of Hand and Reconstructive Microsurgery, University \\ Orthopaedic and Hand Reconstructive Microsurgery Cluster, \\ National University Health System, Singapore, Singapore
}

\begin{abstract}
Address for correspondence Sandeep J. Sebastin, MBBS, MMed (Surgery), Department of Hand and Reconstructive Microsurgery, National University Health System, 1E Kent Ridge Road, NUHS Tower Block, Level 11, Singapore 119228, Singapore

(e-mail: sandeep_sebastin@nuhs.edu.sg).
\end{abstract}

Indian J Plast Surg 2019;52:26-36

\begin{abstract}
Lower extremity soft tissue defects frequently result from high-energy trauma or oncological resection. The lack of suitable muscle flap options for the distal leg and foot makes defects in these locations especially challenging to reconstruct and free tissue transfer is commonly used. Another option that has become more popular in the past two decades are pedicled perforator flaps. Based on a thorough literature review and the authors' experience on leg perforator flaps for over a decade, this article presents a historical review, the anatomical basis of common perforator flaps of the leg and

Keywords

- foot defects

- leg defects

- pedicled flap

- perforator flap

- propeller flap foot, patient selection, wound selection, perforator selection, flap design, surgical techniques, refinements, and postoperative care. A review of the clinical outcomes and complications of these flaps was also performed and was noted to be comparable to the outcomes of free tissue transfer with significantly lower total flap failure rate. It is hoped that this review will assist surgeons in the formulation of a comprehensive step-by-step guide in performing pedicled perforator flap reconstruction of the lower extremity.
\end{abstract}

\section{Introduction}

Lower extremity soft tissue defects frequently result from high-energy trauma or oncological resection. Soft tissue defects of the thigh are comparatively easier to resurface because the femur is surrounded by muscles, allowing defects to be resurfaced with skin grafts or local muscle flaps. In contrast, the relatively superficial location of the tibia and bones of the foot often result in wounds of the leg and foot needing flap coverage. The lack of local muscle flap options for the distal leg and foot makes defects in these locations challenging to reconstruct and free tissue transfers are frequently required. ${ }^{1}$ An option that has been popularized in the past two decades are pedicled perforator flaps.

A perforator flap is a cutaneous or subcutaneous flap that is vascularized by one (or more) perforating vessels arising from underlying deeper vessels. The isolated perforator(s) is mobilized and dissected free with the overlying tissue that it supplies, enabling flap movement. While simple advancement or transposition may suffice in selected cases, these flaps are typically deployed in a propeller fashion using the isolated perforator as the axis of rotation. Advantages of pedicled perforator flaps include (1) "Like-for-like" replacement of tissue as the donor site is in the vicinity of the defect; (2) reduced donor site morbidity with preservation of the source artery and muscle and possibility of complete or partial linear closure of the donor defect; (3) technically less demanding and are faster to perform than free tissue transfers. ${ }^{2,3}$

\section{Historical Review}

The first pedicled perforator flap for the lower limb was probably described by Yoshimura et al in 1985, though he did not name it as such. ${ }^{4} \mathrm{He}$ described the peroneal island flap, based on cutaneous perforators from the peroneal arterial system. Multiple perforator flaps for the lower limb based on the major vessels have been described since. The idea of perforator flaps was suggested by Kroll and Rosenfield in 1988. ${ }^{5}$ They said that perforator flaps combine the reliability of musculocutaneous flaps with the reduced donor site morbidity associated with skin flaps. In 1989, Koshima
DOI https://doi.org/

10.1055/s-0039-1688103

ISSN 0970-0358.
(C)2019 Association of Plastic

Surgeons of India
License terms

(이 (1) $\Theta \circledast$ 
and Soeda ${ }^{6}$ described an inferior epigastric artery skin flap without the rectus abdominis muscle noting that a large flap could be raised without any muscle and that it could rely on just one muscle perforator. This kicked off the era of the perforator flap.

In 1991, Hyakusoku et al ${ }^{7}$ introduced the "propeller" type flap, based on a subcutaneous pedicle that could be rotated $90^{\circ}$ akin to a propeller's rotation. Hallock ${ }^{8}$ used the same name for a flap similar to Hyakusoku's description, but with the flap based on a skeletonized perforator. This enabled the flap to be rotated up to $180^{\circ}$, increasing its reach and allowing the donor site to be closed linearly. Due to the growing popularity of these flaps, the "Gent" consensus ${ }^{9}$ and the "Tokyo" consensus ${ }^{10}$ defined and standardized the classification for these new types of flaps in 2003 and 2011, respectively.

A perforator is defined as a vessel originating from a named axial vessel that traverses deeper tissues to reach the subcutaneous tissue and skin. Before the era of perforator flaps, Mathes and Nahai ${ }^{11}$ had already developed a vascular classification system for fascia/fasciocutaneous flaps where three types of pedicles are mentioned: type A (direct cutaneous), type B (septocutaneous), and type C (musculocutaneous). The "Gent" consensus ${ }^{9}$ expounded on this simple principle and described five types of perforators: (1) direct perforators traversing only deep fascia; (2) indirect muscle perforators primarily supplying subcutaneous tissues; (3) indirect muscle perforators primarily supplying muscle but giving off secondary branches to subcutaneous tissues; (4) indirect muscle perforators traversing muscle but exclusively supplying subcutaneous tissues; (5) indirect septal perforators that traverse an intermuscular septum (-Fig. 1).

The exact definition of what constitutes a perforator flap has been debated over the years. Purists only consider perforator flaps that require muscle dissection as "true" perforator flaps and many do not consider flaps supplied by direct perforators as perforator flaps. The "Gent" consensus ${ }^{9}$ defines a perforator flap as a unit of skin and/or subcutaneous tissue supplied by an isolated perforator that traverses through or in between deeper tissues (usually muscle). Depending on the course of the perforator, the flap may be called a muscle perforator flap or a septal perforator flap.

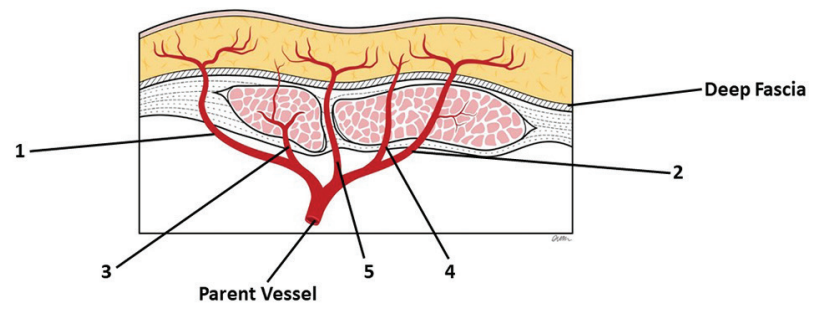

Fig. 1 Perforator classification based on the "Gent" consensus: (1) Direct perforators traversing only deep fascia; (2) Indirect muscle perforators primarily supplying subcutaneous tissues; (3) Indirect muscle perforators primarily supplying muscle but giving off secondary branches to subcutaneous tissues; (4) Indirect muscle perforators traversing muscle but exclusively supplying subcutaneous tissues; (5) Indirect septal perforators that traverse an intermuscular septum.

\section{Angiosome and Perforasome Theory}

Taylor and Palmer ${ }^{12}$ described the angiosome theory in 1987 and identified 40 angiosome regions. Cadaveric studies showed that blood supply was continuous in a three-dimensional network of vessels in all tissue layers. Analogous to a sensory dermatome, an angiosome is a territory of tissue supplied by a common source artery. Adjacent angiosomes are interconnected via intervening smaller caliber vessels typically referred to as choke vessels. In principle, an axial-pattern flap can support an additional angiosome of tissue that is perfused via intervening choke vessels in a random cutaneous pattern (beyond the domain of the main pedicle).

The perforasome is a more recent term coined following deeper exploration of the vascular territory of a single perforator. A perforasome is defined as a unique vascular region supplied by a single perforator. The theory is based on the increased filling pressure and hyperperfusion of the selected perforator, allowing extensive interperforator flow to adjacent perforasomes via the recruitment and opening of linking vessels. Based on a cadaveric study with 217 flaps, Saint-Cyr et $\mathrm{al}^{13}$ described four principles of perforasomes. First, adjacent perforasomes are interlinked via direct (interperforator flow) and indirect linking vessels (subdermal plexus). Normally, these linking vessels are in a collapsed state and open up when a flap is raised on an isolated perforator. As per the choke vessel principle, this interperforator flow mechanism allows a large flap to rely on just one reliable perforator. Second, consideration of flap planning and the positioning of the skin paddle has to take into to account the direction of flow of the linking vessels. This is axial in the limbs and perpendicular to the midline in the trunk. Third, perforasomes are preferentially filled by perforators originating from the same source artery as opposed to perforators originating from an adjacent source artery. This implies that whenever possible, one should limit flap design to the territory of the source artery to maximize vascular filling and density. Finally, with regard to perforators adjacent to a joint, the flow is usually in a direction away from the joint. In contrast, the flow in perforators located at the midpoint between two joints or in the trunk is multidirectional. Linking vessels found between two adjacent perforators were also noted to have a bidirectional flow.

\section{Vascular Anatomy of the Leg and the Associated Perforators}

The major arteries of the leg originate from the popliteal artery at the lower border of the popliteus muscle, which typically corresponds to the level of the tibial tuberosity. At this level, the popliteal artery divides into the tibioperoneal trunk and the anterior tibial artery (ATA). The tibioperoneal trunk divides into the posterior tibial artery (PTA) and the peroneal artery (PA) 20 to 30 $\mathrm{mm}$ distal to the origin of the tibioperoneal trunk. ${ }^{14}$ The venous drainage in perforator flaps is via the small venae commitantes accompanying the perforating artery. ${ }^{15}$ 


\section{Anterior Tibial Perforators}

The ATA passes into the anterior compartment of the leg via the interosseous membrane, accompanied by the deep peroneal nerve. At the level of the malleoli, the ATA gives off the medial and lateral malleolar arteries. At the midpoint of the malleoli, it becomes the dorsalis pedis (DP) artery, which gives off the medial and lateral tarsal arteries, the arcuate artery and continues as the first dorsal metatarsal artery (DMtA). It terminates in the first web by joining the deep plantar artery that originates from the deep plantar arch.

The ATA angiosome encompasses the anterior compartment with the lateral boundary being the fibula and the anterior tibia comprising the medial boundary. ${ }^{15}$ There are $\sim 6 \pm 3$ musculocutaneous and septocutaneous perforators (-Fig. 2). ${ }^{17}$ The proximal perforators are the largest, emerging predominantly from intermuscular septae 21 to $26 \mathrm{~cm}$ above the intermalleolar line. Perforators are smaller distally and are commonly found between the tendons of the muscles of the anterior compartment $\sim 4$ to $9 \mathrm{~cm}$ above the intermalleolar line. ${ }^{18}$ Distally, one to two perforators emerge from the ATA just above extensor retinaculum, giving off branches anterolaterally and anteromedially that supply the skin over the anterior portions of the malleoli. At the ankle, the vessels from the ATA anastomose with branches from the PTA and PA. ${ }^{19}$ An example of a perforator flap based on the distal anterolateral perforators of the ATA is demonstrated in - Fig. 3. The branch from the ATA that travels anterolaterally traverses the deep aspect of the extensor tendons and emerges in front of the lateral malleolus. Here, it gives off deep and superficial branches. The branches from the superficial aspect travels superiorly and terminates in the skin (anterolateral malleolar flap). The branch that travels anteromedially gives off two to three small branches that supply the skin (anteromedial malleolar flap), following the configuration of the anterolateral branches. ${ }^{19}$

The ATA continues as the DP in front of the ankle joint, supplying the foot dorsum. ${ }^{16}$ Traveling underneath the extensor hallucis longus, the DP dips plantarwards through the interosseous muscle to join the plantar arch and gives off the arcuate artery and the first DMtA to the first web space. ${ }^{20}$ In two cadaveric studies, at least one perforator from the DP was consistently found to supply the skin of the dorsum. Winaikosol et $\mathrm{al}^{20}$ quote the perforator to be found $3.25 \mathrm{~cm}$
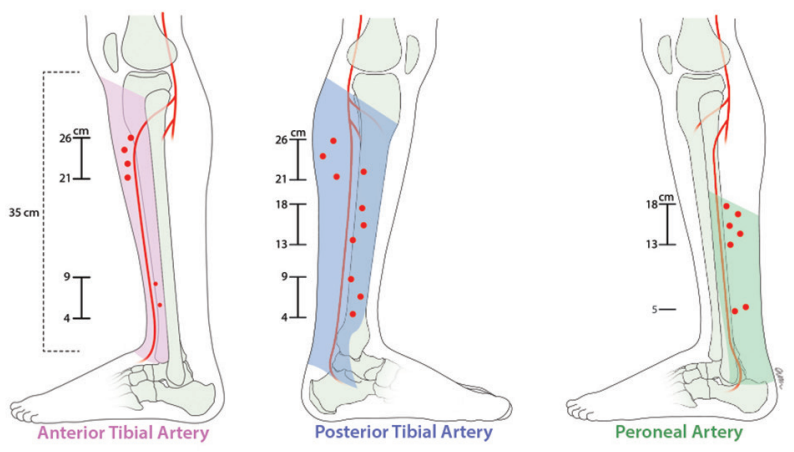

Fig. 2 Distribution of anterior tibial artery, posterior tibial artery, and peroneal artery perforators and their territories. proximal to the metatarsophalangeal joint, while Russo et al ${ }^{21}$ quote this distance as $4.0 \mathrm{~cm}$. Both these studies describe a eliable adipofascial turnover flap based on this perforator, which has been used to cover distal foot defects, although propeller perforator flaps based on this may also be utilized. An example of a perforator flap based off the first DMtA is demonstrated in - Fig. 4.

The second to fourth DMtAs arise from the arcuate arteries and run forward to supply the web spaces and the toes. Two to five cutaneous perforators can consistently be found arising from each DMtA with the distal-most perforator usually having the most significant vessel caliber of $\sim 0.5$ to $0.7 \mathrm{~mm} .^{22}$ The perforator from the DMtAs can regularly be found distal to the juncture of the extensor tendons between the metatarsal heads. Flaps based on the distal perforators of the DMtAs have been used for coverage of small defects on the foot and toes.
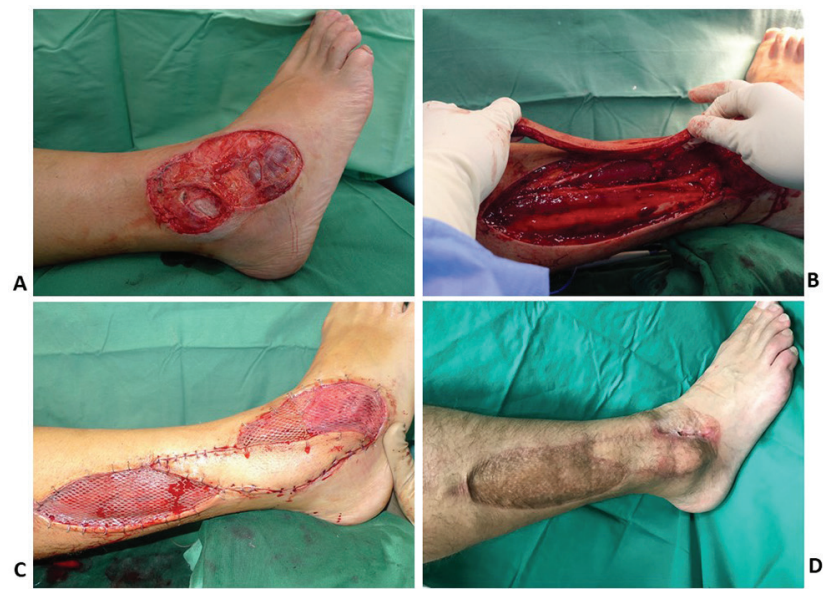

Fig. 3 Anterior tibial artery perforator flap: (A) Traumatic wound of the lateral aspect of the ankle with exposed lateral malleolus. (B) The anterior tibial artery perforator twin-bladed propeller flap has been raised with the isolated perforator indicated by the blue arrow. (C) The flap has been rotated to cover the critical area of the defect, with the noncritical area and the donor site skin grafted. (D) Final clinical result.
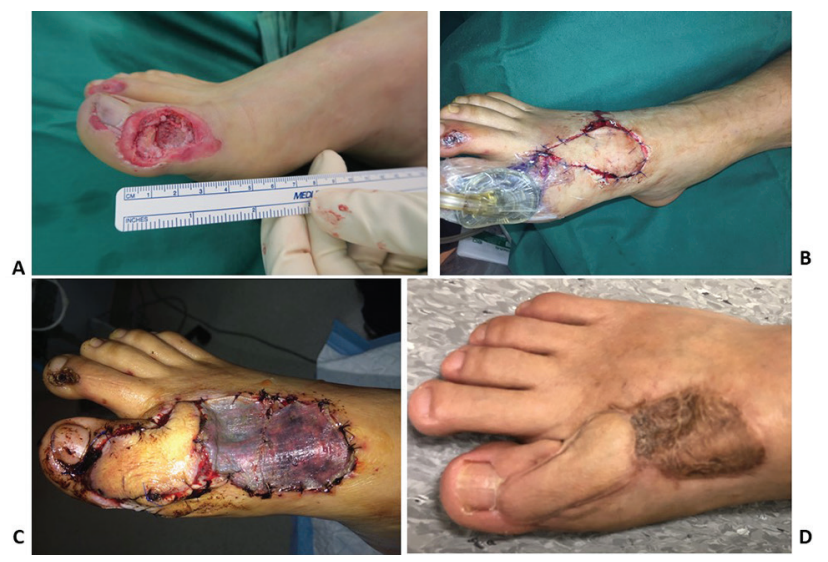

Fig. 4 First dorsal metatarsal artery perforator flap: (A) Deep wound over dorsal lateral aspect of right big toe with exposed bone. (B) First dorsal metatarsal artery perforator twin-bladed propeller flap raised. The flap was noted to have sluggish perfusion on islanding; hence, the decision was made to delay the flap by leaving it in its donor site and placing a negative pressure wound therapy dressing on the wound. (C) After 1 week, the flap was rotated into the defect with the donor site skin grafted. (D) Final clinical result. 


\section{Posterior Tibial Perforators}

Passing downward, the PTA lies on the posterior aspect of the tibialis posterior muscle at the proximal portion of the leg and at the posteromedial aspect of the tibia at the distal portion. Before its termination into the medial and lateral plantar arteries, it passes posterior to the medial malleolus. Just prior to its termination, the PTA gives off posteromedial branches that anastomose with the medial malleolar artery. The PTA angiosome starts from the anteromedial border of the tibia, extending posteriorly to the central raphe of the Achilles tendon at the midline of the calf. ${ }^{16}$ According to Geddes et $\mathrm{al}^{17}$ the PTA gives off $\sim 10 \pm 4$ cutaneous perforators, while some others have quoted several clusters of 3 to 5 perforators (-Fig. 2). ${ }^{23}$ It is here that the largest perforators of the leg are found especially in the middle third of the septum between the soleus and the flexor digitorum longus where perforators with diameters up to $1.5 \mathrm{~mm}$ have been found. Schaverien and Saint-Cyr ${ }^{18}$ described three clusters of perforators found at 4 to $9 \mathrm{~cm}$, 13 to $18 \mathrm{~cm}$, and 21 to $26 \mathrm{~cm}$ from the intermalleolar line. Other authors have noted the significant numbers of perforators in the region 5 to $14 \mathrm{~cm}$ above the medial malleolus. $^{23,24}$ While the perforators are predominantly septocutaneous, ${ }^{18}$ musculocutaneous perforators can also be found. ${ }^{16}$ An example of a perforator flap based on the PTA is demonstrated in - Fig. 5.

As the PTA traverses the calcaneal canal, a branch travels posteromedially, perforating the fascia behind the medial malleolus and emerges anteriorly (posteromedial malleolar flap).

The plantar foot is vascularized by two main vessels originating from the PTA, namely the medial plantar artery that supplies the instep region and the lateral plantar artery. The lateral plantar artery initially gives off the medial calcaneal branch which provides the major vascular supply to the heel pad while its subsequent branches supply the lateral midfoot and forefoot. Originating from the PTA in the calcaneal canal, the medial plantar artery sends one to three branches to the medial foot that traverse the septum between the flexor hallucis longus and abductor hallucis muscles. ${ }^{25}$ The most developed branch assumes the role of the medial plantar artery, with its perforators being used in the medial plantar flap. ${ }^{19}$

\section{Peroneal Perforators}

The PA descends behind the fibula, in close association with the flexor hallucis longus, giving off muscular branches and a nutrient artery to the fibula. It terminates by taking part in the anastomosis with the lateral malleolar artery around the ankle. ${ }^{16}$ The lateral border of the PA angiosome is the central raphe of the Achilles tendon, while the medial border corresponds to the posterior border of the fibula.

The posterolateral skin of the leg is supplied by $5 \pm 2$ musculocutaneous and septocutaneous perforators located at 3 to $5 \mathrm{~cm}$ intervals that travel in close proximity to the posterolateral intramuscular septum (-Fig. 2). ${ }^{16,17}$ In the proximal leg, the perforators emerge from the soleus or peroneus longus muscles, while in the distal leg they emerge in the septum of the flexor hallucis longus and the peroneus brevis. Most of the peroneal perforators are found 13 to $18 \mathrm{~cm}$ above the lateral malleolus emerging from the septum of the flexor hallucis longus and peroneus brevis. Distal perforators from the PA dominate in the lateral aspect of the ankle. Approximately $5 \mathrm{~cm}$ proximal to the lateral malleolus, a perforator can be found that commonly divides into two branches after it traverses the interosseous membrane. The two branches are the superficial cutaneous branch (lateral supramalleolar flap) and a deep descending branch. ${ }^{26}$ The superficial branch supplies the distal half of the leg from the tibial crest to the posterior fibula. It is worth noting that the lateral malleolar flap is better described in literature while there is sparse mention of the medial malleolar flap. In the case series written by
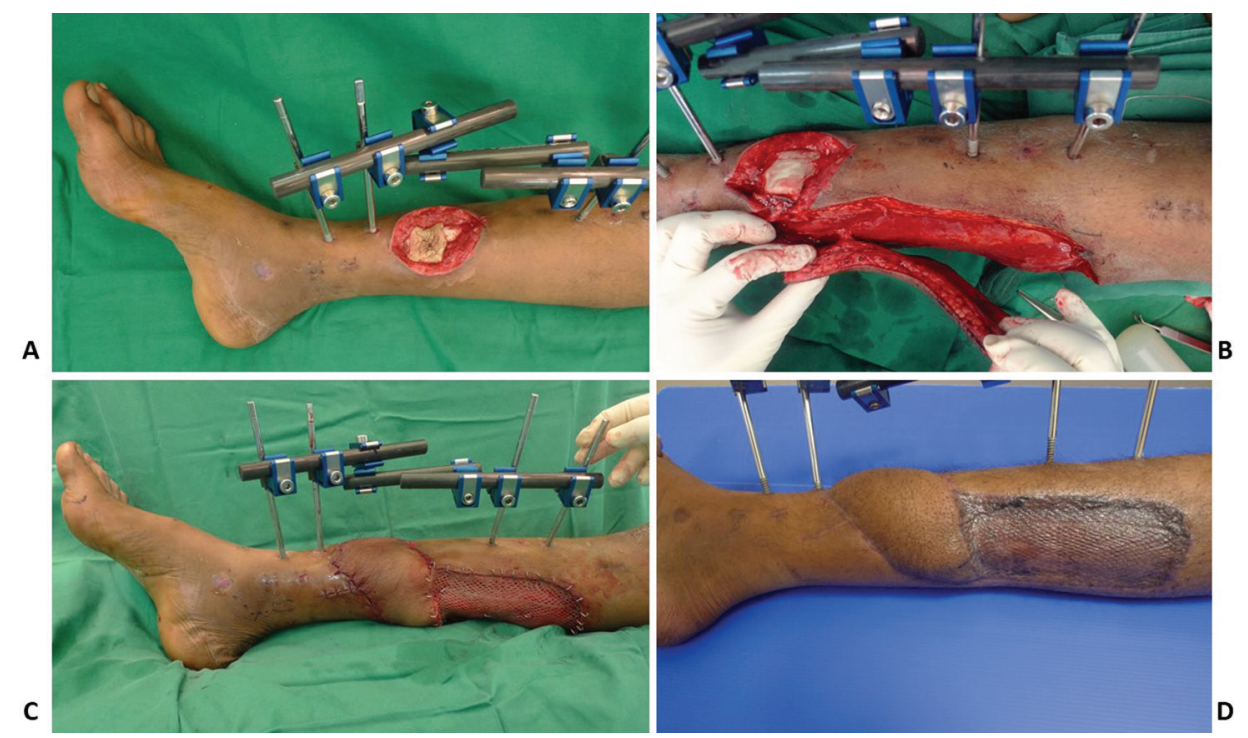

Fig. 5 Posterior tibial artery perforator flap: (A) Defect located over the anterolateral aspect of the distal leg with the tibia exposed. (B) Posterior tibial artery perforator twin-bladed propeller flap raised with the isolated perforator located just proximal to the defect. (C) The flap was rotated $\sim 140^{\circ}$ for coverage of the defect with the donor site skin grafted. (D) Final clinical result. 
Koshima et $\mathrm{al}^{19}$ of the 10 cases described, only one medial malleolar flap was utilized. A perforator flap based on the PA perforator is demonstrated in - Fig. 6. Finally, the PA terminates as the anterior perforating branch supplying the anterolateral upper ankle and the lateral calcaneal branch that supplies the plantar portion of the heel.

\section{Approach to a Defect}

\section{Patient Selection}

Reconstruction starts with appropriate patient and wound selection. While healthy young patients are the ideal surgical candidates, perforator flaps may be considered for patients with multiple comorbidities who are poor candidates for a free tissue transfer. Peripheral vascular disease and/or insulin dependent diabetes are relative contraindications to perforator flaps, with significant flap necrosis rates observed. ${ }^{24}$ However, it has been noted that the atherosclerosis rates in the PA are lower and they are usually affected last, allowing perforator flaps to be harvested based on the PA in elderly atherosclerotic and/ or diabetic patients ( - Fig. 6 ). ${ }^{27}$

\section{Wound Selection}

The next step is careful assessment of the wound. While it has been quoted that small-to-medium sized defects are suitable for coverage with pedicled perforator flaps, ${ }^{3}$ the definition of small and medium is arbitrary. To objectively assess the size of a wound, we propose to divide the leg

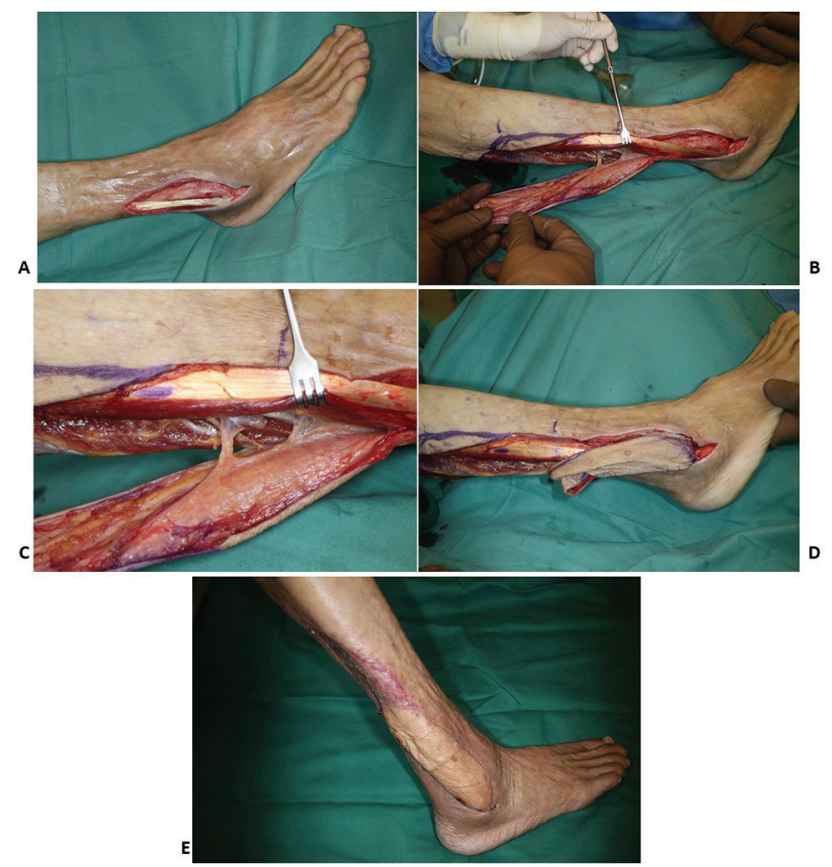

Fig. 6 Peroneal artery perforator flap: (A) Wound of the lateral aspect of the distal foot and ankle with exposed tendon from an infected implant that was removed from a 70-year-old diabetic lady. (B) Posteroanterior (PA) perforator unibladed propeller flap raised with the perforator emerging from the posterior intermuscular septum. (C) Close-up view of the PA perforator. (D) Flap rotated $160^{\circ}$ to cover defect. Note the intact skin bridge with the dog-ear. (E) Final clinical result with dog-ear well settled. (from knee to ankle joint) equally into thirds longitudinally (by length) and circumferentially (by circumference with the palpable medial edge of the tibia being the starting reference point for division) (-Fig. 7). Circumferentially, this creates an anterolateral surface, an anteromedial surface, and a posterior surface. Combining this with the longitudinal divisions, this creates a total of nine divisions on the leg. A small defect is one that involves one division, while a medium defect is one that involves two adjacent divisions. The involvement of three or more divisions translates to a large defect. Based on this classification, perforator flaps are best suited for small defects.

After adequate debridement, the skin surrounding the defect must be examined for features of injury that preclude

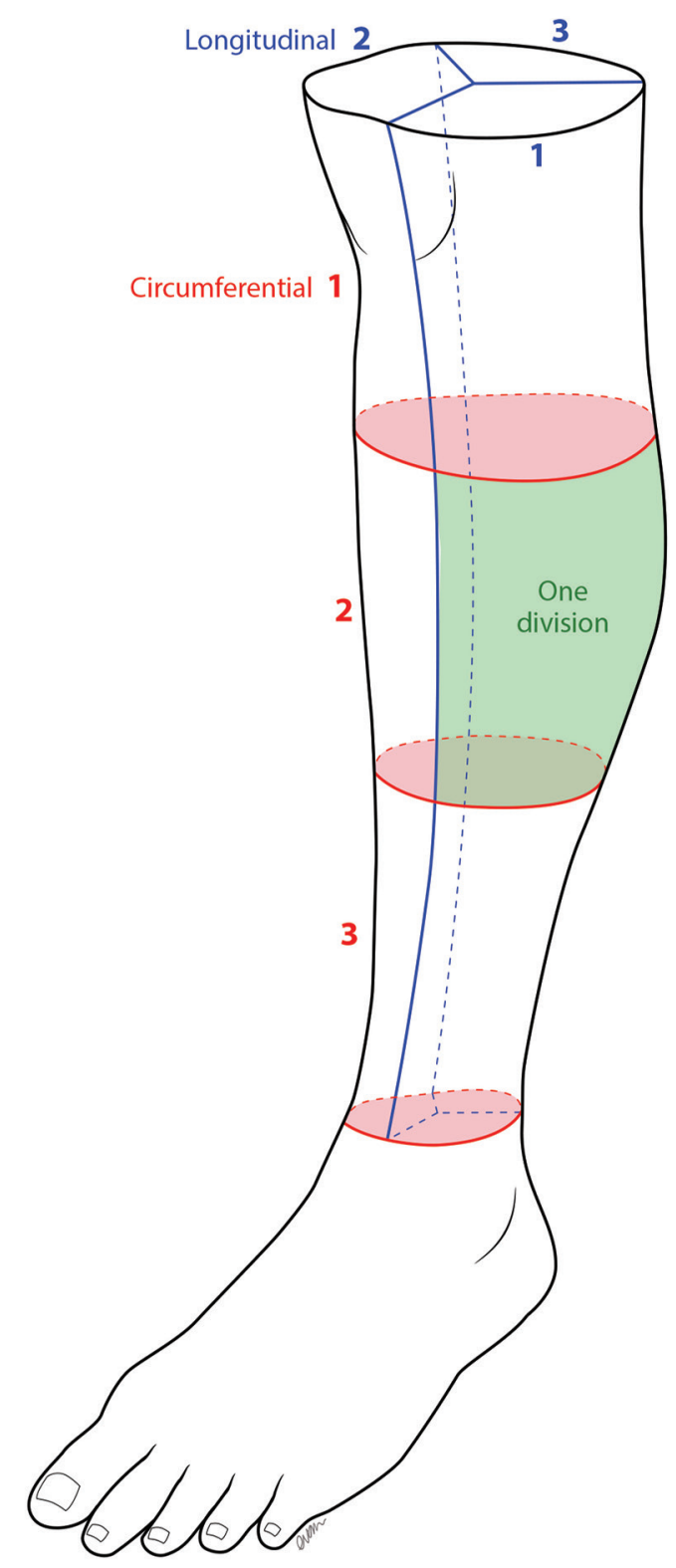

Fig. 7 The leg is divided into thirds longitudinally and circumferentially. This creates a total of nine divisions on the leg. A small defect is one that involves one division, while a medium defect involves two divisions. The involvement of three or more divisions translates to a large defect. 
the use of perforators adjacent to the defect. These features include discoloration, bruising, prolonged capillary refill, dark bleeding from the skin edges, and contusion of the underlying muscles. Degloving of the skin in a suprafascial or subfascial plane also indicates injury to the adjacent perforators.

\section{Perforator Selection}

Multiple perforator flaps are available for selection in the leg and foot and are chosen based on the proximity and size of the defect. The details of commonly used perforator flaps are summarized in $\boldsymbol{- T a b l e ~} \mathbf{1}$.

Several well-known modalities for preoperative identification of perforators include handheld Doppler, color Doppler, duplex ultrasound, arteriography, high-resolution computed tomography, and magnetic resonance angiography. While useful at delineating vascular anatomy, positive findings in these investigations do not correlate to final flap survival and outcome. ${ }^{23}$ Despite this, handheld Doppler is useful as a guide for preoperative marking of suitable perforators for flap design.

Following the territory of perforators as outlined above, the approximate location of suitable perforators is marked on the skin with the assistance of a handheld Doppler device. There is usually no difficulty in detecting Doppler signals that are loud, pulsatile, and high-pitched. ${ }^{28}$ The intensity of the sound may give the surgeon an idea of the size of the perforator and allows the surgeon to choose the tentative perforator to base the flap on. The cutaneous perforators are marked with indelible ink with distinct markings for the perforator with the most prominent signal. Differentiating between main vessels and perforators is possible with practice. The sound from the main vessel is louder and will still be audible when moving proximally or distally, while the sound generated by a perforator is only heard in one distinct location and usually disappears on placing more pressure over the area with the probe as the pressure will block off the flow. ${ }^{29}$ Note that these markings are merely a guide and can generate erroneous findings as in the extremities, main vessels run close to the skin. ${ }^{3}$ There is no replacement for accurate identification and isolation of perforators via exploratory incisions and direct visualization of the perforator is vital.

Ideally, a perforator closest to the defect allows the defect to be covered with minimal wastage of skin. This, however, presents us with a conundrum, as perforators that are closest to a traumatic defect are also theoretically closer to the zone of injury. When determining suitability of a perforator for a flap intraoperatively, we choose a perforator where it is possible to identify the perforator artery and its draining venae comitantes distinctly. If a distinction between the artery and the venae comitantes cannot be made, we do not use it. Although this perforator may have an audible signal on Doppler, the venae comitantes are likely injured and there is an increased risk of venous congestion if a flap is raised based on this perforator.

Table 1 Details of the commonly used perforator flaps of the leg and foot

\begin{tabular}{|c|c|c|c|}
\hline Main vessel & Territory & Location of major perforator(s) & Axis \\
\hline $\begin{array}{l}\text { Anterior } \\
\text { tibial }^{16,18}\end{array}$ & $\begin{array}{l}\text { Anterior medial border of the } \\
\text { tibia extending laterally to the } \\
\text { lateral border of fibula }\end{array}$ & $\begin{array}{l}\text { Proximal: } 21-26 \mathrm{~cm} \text { proximal to } \\
\text { intermalleolar line } \\
\text { Distal: } 4-9 \mathrm{~cm} \text { proximal to } \\
\text { intermalleolar line }\end{array}$ & $\begin{array}{l}\text { Proximal: Between the tibia and } \\
\text { tibialis anterior } \\
\text { Distal: Septum between extensor } \\
\text { digitorum longus and peroneus } \\
\text { longus, between tibialis anterior and } \\
\text { extensor digitorum longus }\end{array}$ \\
\hline $\begin{array}{l}\text { Posterior } \\
\text { tibial }^{23,24}\end{array}$ & $\begin{array}{l}\text { Anterior medial border of the } \\
\text { tibia extending medially to the } \\
\text { midline of the calf over the } \\
\text { central raphe of the Achilles } \\
\text { tendon }\end{array}$ & $\begin{array}{l}\text { Proximal: } 21-26 \mathrm{~cm} \text { proximal to } \\
\text { intermalleolar line } \\
\text { Middle: } 13-18 \mathrm{~cm} \text { proximal to } \\
\text { intermalleolar line } \\
\text { Distal: } 4-9 \mathrm{~cm} \text { proximal to } \\
\text { intermalleolar line }\end{array}$ & $\begin{array}{l}\text { Septum between flexor digitorum } \\
\text { longus and soleus }\end{array}$ \\
\hline Peroneal ${ }^{16,18}$ & $\begin{array}{l}\text { Central raphe of the Achilles } \\
\text { tendon extending laterally } \\
\text { to the anterior intermuscular } \\
\text { segment }\end{array}$ & $\begin{array}{l}\text { Proximal: } 13-18 \mathrm{~cm} \text { proximal to tip } \\
\text { of lateral malleolus } \\
\text { Distal: } 5 \mathrm{~cm} \text { proximal to tip of lateral } \\
\text { malleolus }\end{array}$ & $\begin{array}{l}\text { Septum between flexor hallucis } \\
\text { longus and peroneus brevis }\end{array}$ \\
\hline $\begin{array}{l}\text { Lateral } \\
\text { malleolar }\end{array}$ & $\begin{array}{l}\text { Lower half of leg from the tibi- } \\
\text { al crest to the posterior margin } \\
\text { of the fibula }\end{array}$ & $\begin{array}{l}0-5 \mathrm{~cm} \text { proximal to tip of lateral } \\
\text { malleolus }\end{array}$ & $\begin{array}{l}\text { Groove between the tibia and the } \\
\text { fibula, just proximal to the distal } \\
\text { tibiofibular ligament }\end{array}$ \\
\hline $\begin{array}{l}\text { Dorsalis } \\
\text { pedis }^{20,21}\end{array}$ & $\begin{array}{l}\text { Medial half of dorsum of the } \\
\text { foot }\end{array}$ & $\begin{array}{l}2.5-4.5 \mathrm{~cm} \text { proximal to the first } \\
\text { metatarsophalangeal joint }\end{array}$ & $\begin{array}{l}\text { Mid-malleolar point of ankle joint to } \\
\text { first web space of foot }\end{array}$ \\
\hline $\begin{array}{l}\text { Dorsal } \\
\text { metatarsal } \\
\text { artery } \\
(2 \mathrm{nd}-4 \mathrm{th})^{22}\end{array}$ & $\begin{array}{l}\text { Dorsal skin proximal to corre- } \\
\text { sponding web space }\end{array}$ & $\begin{array}{l}\text { Between the heads of the } \\
\text { metatarsals and distal to the juncture } \\
\text { of the extensor tendons }\end{array}$ & $\begin{array}{l}\text { Superficial to or within the corre- } \\
\text { sponding interosseous muscle }\end{array}$ \\
\hline $\begin{array}{l}\text { Medial } \\
\text { plantar }^{25}\end{array}$ & $\begin{array}{l}\text { Medial half of sole of the } \\
\text { foot anterior to the medial } \\
\text { malleolus }\end{array}$ & $\begin{array}{l}\text { Axis between the sustentaculum of } \\
\text { the talus and the medial aspect of } \\
\text { the head of the first metatarsal }\end{array}$ & $\begin{array}{l}\text { Septum between the flexor hallucis } \\
\text { longus and abductor hallucis }\end{array}$ \\
\hline
\end{tabular}




\section{Flap Design}

The design of pedicled perforator flaps may be classified according to their movement into advancement, transposition, rotation, or propeller flaps. ${ }^{30}$ Another way to classify the design is based on vascularity into islanded and peninsular flaps. An islanded flap is vascularized only by the perforator and includes designs like the twin-bladed propeller, VY, and keystone. Peninsular flaps receive vascularization by the intact skin bridge in addition to the perforator and include the unibladed propeller flap and the traditional rotation and transposition flaps. This perforator flap design with the intact skin bridge has also been described as a perforator plus flap. ${ }^{31}$ The main advantage of an islanded design is increased mobility, but it is associated with an increased risk of distal ischemia, necrosis, and venous congestion. Peninsular flaps mitigate these risks but do not provide as much mobility. ${ }^{3,30,31}$ This disadvantage can be overcome to a certain degree with back-cuts or Burow triangles that would allow greater movement of peninsular flaps with the isolated perforator serving as an "insurance."

As discussed earlier, the perforator should be selected as close as possible to the defect as this denotes the pivot point of the flap. The length of the planned flap is designed and this should correspond to the distance of the pivot point to the furthest edge of the defect. Similarly, the width of the planned flap is determined based on the width of the defect. Design of the flap should also take into account the shape and overall dimensions of the defect. The commonest islanded perforator flap design in the lower limb is the twin-bladed propeller (two blades of unequal sizes). The perforator itself is located at the junction of the two blades with the distal blade representing the skin separating the perforator and the edge of the defect. A $180^{\circ}$ rotation of the propeller around the axis of the perforator allows the larger proximal blade to cover the defect. The distal blade allows partial or complete closure of the defect left behind by the proximal blade (-Figs. $\mathbf{3}, \mathbf{4}, \mathbf{5}, \mathbf{8}$ ). The other islanded perforator flap designs are used less frequently. In a VY advancement flap, the

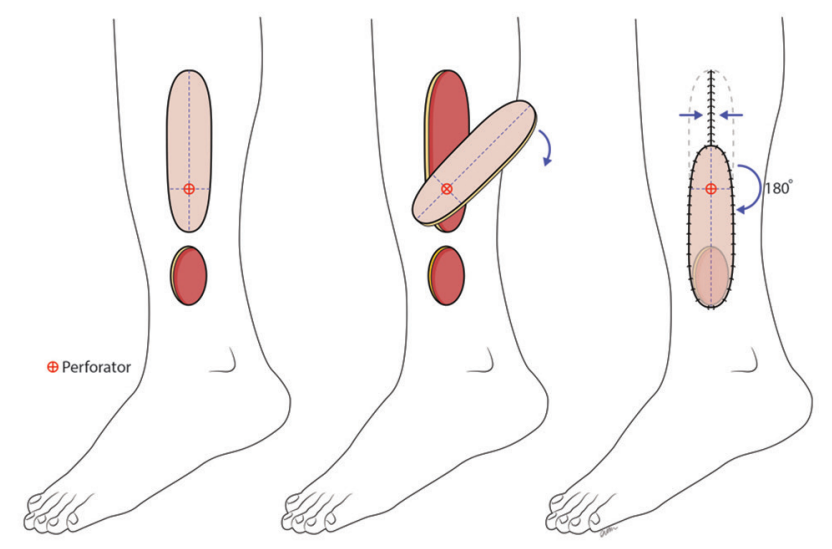

Fig. 8 Twin-bladed propeller flap: The flap can be rotated up to $180^{\circ}$ on the axis of the perforator. The longer blade is inset into the defect, while the shorter blade is used to cover the distal part of the donor site. island is advanced instead of rotated. Unlike the perforator in a propeller flap that needs to be twisted, the perforator in a VY flap is only mobilized and advanced thus reducing the risk of venous congestion ( $\mathbf{- F i g . 9}$ ). Another advantage of the VY advancement flap is the ease of linear closure of the donor site. The main disadvantage of the VY advancement flap is the limited advancement. The keystone flap is based on a double opposing VY flaps and once again has limited advancement (-Fig. 10).

The unibladed propeller flap is the commonest peninsular perforator flap design used in the leg. It is designed like a propeller flap except that it has only one blade (the proximal blade) with the skin bridge adjacent to the pivot point left intact for supplementary arterial inflow and venous outflow (-Figs. 6 and 11). Keep in mind that leaving a bridge of skin near the pivot point will limit the degree of movement of the flap and leave an unsightly dogear. While this may not be practical for flaps that require a
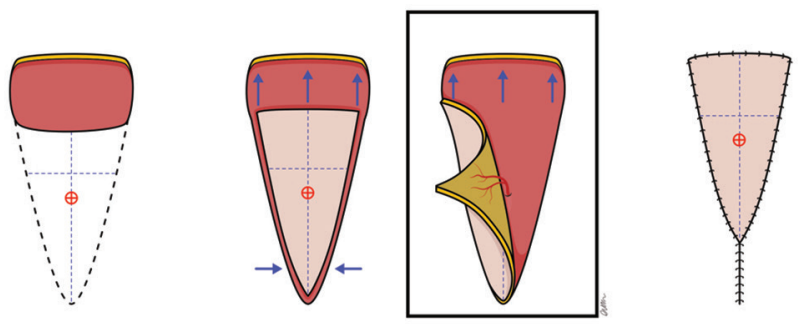

Fig. 9 VY advancement flap: The flap is raised based on a perforator and advanced forward. Additional advancement can be obtained by isolation and dissection of the perforator. The donor site can easily be closed linearly.
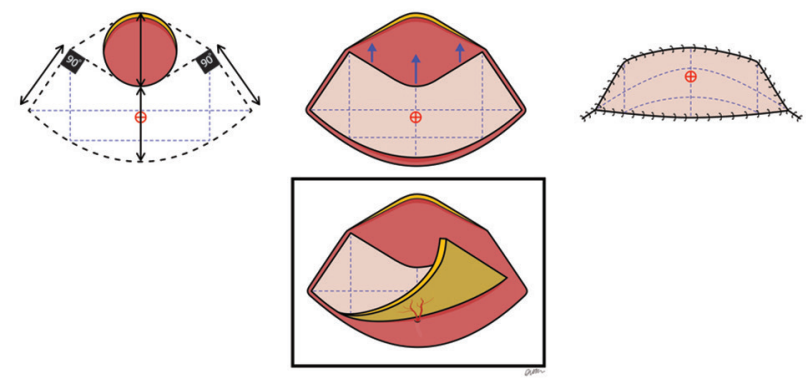

Fig. 10 Keystone (double VY) flap: This flap can be supported by a single perforator and advanced to cover the defect.
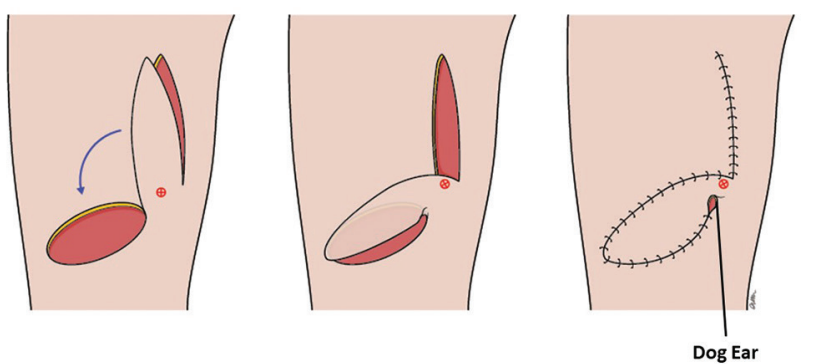

Fig. 11 Unibladed propeller flap designed with skin bridge left intact adjacent to the pivot point. Note the dog-ear present at the pivot point of the flap post-inset. This can be revised at a later stage once the flap has stabilized. 


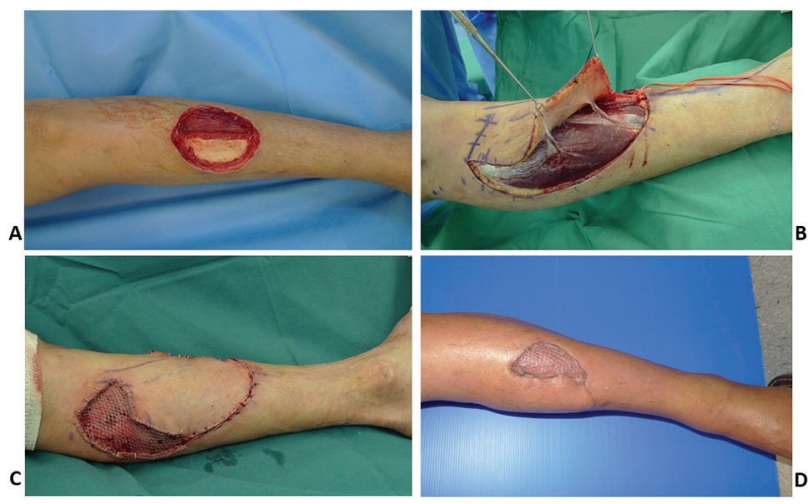

Fig. 12 Perforator-based transposition flap (perforator plus flap): (A) Defect over the anterior portion over the middle third of the leg with exposed tibial shaft. (B) A transposition flap was designed with tissue from the medial aspect of the leg. A musculocutaneous and a septocutaneous perforator were identified and preserved. (C) The flap was transposed for coverage of the exposed tibia with the perforators still intact. The presence of the perforators allowed an aggressive back-cut to made. The noncritical area of the defect and donor site was skin grafted. (D) Final clinical result.

movement of $180^{\circ}$, the additional support the skin bridge provides to flaps that need to rotate less may prove valuable for flaps with perforators of questionable quality or size. The other type of a peninsular perforator flap is the traditional transposition/rotation that includes a known perforator, analogous to a perforator plus flap ( - Fig. 12).

\section{Elevation}

We always elevate our perforator flaps under tourniquet control. This allows a cleaner dissection and better assessment of the perforators. As recommended by multiple authors, 3,24,28,30,32 only one side of the planned flap is initially incised. This incision should be able to serve as the edge of a possible alternative flap in the event that a suitable perforator is not found. ${ }^{3}$ The depth of elevation of the flap can be suprafascial or subfascial depending on the thickness desired and the level of comfort of the surgeon. While a subfascial dissection is technically easier, suprafascial flap elevation leaves the fascia intact and permits a thinner flap to be elevated. ${ }^{32}$ In our opinion, it is best to elevate flaps of the leg in the subfascial plane. The loose areolar tissue in this plane allows easier flap elevation and importantly, the suprafascial plexus ${ }^{33}$ is preserved. In contrast, elevating the flap in the suprafascial plane is more challenging as there is no clear tissue plane and the flap is perfused only by the subdermal plexus. Only experienced surgeons that are very familiar with perforator flaps should attempt suprafascial elevation. Dissection should be performed under loupe magnification for optimal visualization. The dissection proceeds in the direction of the marked perforators and all potential perforators are isolated and preserved. It is advisable to preserve all potential perforators close to the pivot point until flap dissection is complete. If the premarked perforator is deemed unsuitable, one should make an effort to look for other potential perforators and modify the flap design accordingly. At this stage, the pivot point is repositioned based on the visualized perforator(s) and the length of the flap can be adjusted accordingly. If it is determined that a skin bridge is required, the flap may need to be redesigned with greater length as the skin bridge may limit its reach (-Fig. 11). The proximal edge and the other lateral edge of the flap are then incised and the flap raised from proximal to distal until the selected perforator is reached. If there is a reasonable sized cutaneous vein in the proximal edge of the flap, one can mobilize 1 to $2 \mathrm{~cm}$ length of the vein before clipping it. This may be useful for supercharging a congested flap.

Care is then taken to dissect the tissue distal to the site of the perforator. The amount of flap movement required will determine the extent of perforator dissection. While additional dissection increases the reach of the flap, it also increases the risk of injury to the perforator. Moreover, a longer skeletonized pedicle increases the risk of an occlusive twist thereby compromising the blood flow to the flap. In this setting, Georgescu ${ }^{3}$ recommends clearance of fascia and muscular branches associated with the perforator for $2 \mathrm{~cm}$, but less dissection is required if the flap is able to be inset into the defect without tension. If there is more than one perforator, decision regarding perforator selection should take into account its location, size, course, orientation, ability to sustain the flap, and number of venae commitantes. Intraoperative Doppler assessment is a useful adjunct in determining which perforator to select. If the Doppler signals and overall characteristics of the perforators are similar, the perforator nearer to the defect is preferred, enabling further reach of the flap. ${ }^{28}$ Another option is to clamp one of the two perforators with a vessel clamp and assess perfusion based on one perforator. It is also advisable to rest the flap in its native location for 10 to 15 minutes before rotating it into the defect. This allows reperfusion and relief of vasospasm. A vessel that is empty is more likely to get kinked as opposed to a vessel that if filled.

\section{Movement and Inset}

In the case of perforator flaps, there are several factors to consider for rotation of the flap into the defect. First, a decision is made whether or not to island the flap or leave the previously mentioned skin bridge. While propeller flaps are typically islanded, two considerations must be factored in: (1) the degree of rotation required and (2) the ability of the selected perforator to support the flap. The presence of a skin bridge typically limits the flap to $\sim 90^{\circ}$ of rotation; hence if more movement is required, islanding the flap will be ideal. This also improves the cosmetic appearance as maintaining a skin bridge sometimes leaves an unsightly dog-ear. Occasionally, due to a variety of reasons (e.g., small caliber, poor flow, traumatized vessel), the selected perforator is insufficient to support the entire flap. In this case, leaving a bridge of skin as discussed above is helpful as it adds an additional drainage and random pattern blood supply to power the flap. To determine whether this is required, a soft bowel clamp may be applied over the skin bridge to obstruct the blood flow and the flap is observed for $\sim 10$ minutes. If there is no clinical compromise of the flap, the perforator is likely sufficient to power the flap and the flap can be islanded; otherwise, it might be advisable to keep the skin bridge and consider revision of the dog-ear at a later stage. ${ }^{24}$ The soft bowel clamp technique can also be utilized to determine the 
degree of perfusion to the most proximal end (will become distal end after rotation) of the flap. The bowel clamp is placed at the intended site of flap division proximally, the tourniquet released, and flap perfusion assessed.

For islanded flaps that need to be rotated $180^{\circ}$, it is important to determine the direction of rotation (clockwise or counter-clockwise) by observing which direction causes increased torsion or kinking of the pedicle. The ideal axis of rotation is one where twisting and kinking are minimized. ${ }^{34}$ Transfer and inset of the flap are only undertaken after ensuring the adequacy of vascularity of the flap while it lies in its native position. ${ }^{32}$ If the flap perfusion is poor in the native position, the following steps can be taken. Relieve any vasospasm by irrigating the perforator with 2 to $4 \%$ lidocaine or papaverine $(30 \mathrm{mg} / \mathrm{mL})$ and the flap with warm saline. Ask the anesthetist regarding the blood pressure and if required, consider fluid boluses. It is also important to tell the anesthetist not to use vasopressor agents (e.g., phenylephrine, ephedrine, adrenaline, noradrenaline) to improve the blood pressure. If the flap perfusion does not improve in 20 to 30 minutes, we would suture the flap loosely in its native position and see the behavior of the flap in the ward. If the flap survives entirely, we would consider transfer after 5 to 7 days. If a portion of the flap is not perfused (usually the distal and critical portion), the flap has to be abandoned and another flap planned. Occasionally, flap perfusion is poor once it is transferred. In this case, one may attempt to rotate the flap in the opposite direction and observe its viability. If perfusion is still poor, the flap should be returned to its native position, and one should consider flap elevation as a delay procedure and transfer the flap after 5 to 7 days (-Fig. 4). In the scenario of flap congestion, one may also consider the option of supercharging the flap. Both Ono et $\mathrm{al}^{35}$ and Horta et $\mathrm{al}^{36}$ have described supercharging perforator flaps to increase flap viability, particularly for larger flaps harvested beyond the designated perforasome. Venous congestion is the most common postoperative complication and supercharging is a practical strategy to prevent this. Augmenting venous drainage has been shown to significantly improve flap viability as opposed to augmenting only the arterial inflow. ${ }^{37}$

The flap should be inset loosely to prevent skin edge necrosis. Meticulous hemostasis is necessary to permit partial donor site closure prior to tourniquet release. Closure can be challenging post-tourniquet release due to the reactive edema. ${ }^{29}$ The donor site should not be closed under tension (skin flaps on either edge of the suture line appear white) as this may compromise the source vessel and reduce the flap's blood supply. A tight flap to defect edge interface can always be partially sutured and a skin graft can be placed over the remaining noncritical defect. ${ }^{3}$ Carefully positioned drains can be placed, if necessary.

The role of delay in lower limb perforator flaps has still not yet been thoroughly studied and its role in increasing the flap resistance to torsion of its pedicle is questionable. Surgical delay has been well described and its efficacy in improving flap survival has been thoroughly established. ${ }^{38,39}$ Even in the setting of perforator flaps, delay has proven to enhance vascularity and prevent fat necrosis. Acartürk et a ${ }^{40}$ performed a study on staged elevation in rats and showed that elevation of a perforator flap in stages effectively enhanced the survival rate of a flap. Christiano and Rosson ${ }^{41}$ showed that utilization of the delay phenomenon in deep inferior epigastric perforator flaps showing vascular compromise before attachment enhanced the vascularity of the flap and prevented fat necrosis. Bektas et $\mathrm{al}^{42}$ also performed a study on perforator flap in rats regarding the role of delay in increasing the resistance of perforator flaps to torsion of its pedicle. After a delay of 1 week, it was noted that the process had not significantly improved the flap resistance to torsion. The short duration of 1 week and the lack of clinical studies in humans imply that more research in this area is required. However, it is undeniable that surgical delay has its role in recruitment of choke vessels and conditioning the flap to reduced blood supply, even in the setting of perforator flaps. The role of delay can thus be considered in perforator flaps in high-risk patents or where the perforator is of questionable quality.

\section{Postoperative Care}

Postoperatively, bandaging should be soft and light so as to avoid excessive compression to the flap with a small window left uncovered for monitoring of the flap. The limb should be held elevated for edema reduction. No special flap monitoring is usually necessary. All patients are kept on a backslab to minimize movement of adjacent joints for at least the first week and the wounds are inspected 5 to 7 days postoperatively. Any nonabsorbable sutures are removed at 2 weeks.

As mentioned above, venous congestion is the most common complication, and while more commonly occurring at the tip, it can also occur across the entire flap. ${ }^{3}$ If vascular complications occur postoperatively, attempts to salvage the flap include removal of stitches to ease tension, applying local heparinization or the use of leeches. Should the entire flap be compromised, a formal debridement is usually required. If one is fortunate enough, the necrosis is restricted to the skin and subcutaneous tissue, thus enabling the situation to be salvaged with a skin graft.

\section{Outcomes}

Pedicled perforator flaps have been utilized for defects originating from a multitude of etiologies ranging from trauma to oncologic resections to infections and burn injuries with similar success rates. Gir et $\mathrm{a}^{2}$ conducted a systemic review on 186 cases using pedicled perforator flaps and noted that the flaps most commonly used were the PA and the PTA perforator flaps, both accounting for more than $90 \%$ of all flaps. The most common arc of rotation was $180^{\circ}$ for propeller flaps in the systematic review with arcs ranging from $70^{\circ}$ to $180^{\circ}$. The donor site was directly closed in $37.3 \%$ of cases, while the remainder of the cases required skin grafting for donor site coverage.

Common complications reported include total and partial flap necrosis, venous congestion, superficial epidermolysis, and hematoma. In the systematic review by Gir et al, ${ }^{2}$ the overall complication rate was reported at $25.8 \%$. The commonest complication encountered was partial flap 
necrosis comprising $11.3 \%$ of all cases, while venous congestion was the second most common at $8.1 \%$ of all cases. Among cases with complications, only 6.5\% required surgical intervention and the overall flap failure rate was $1.1 \%$. Innocenti et $\mathrm{al}^{43}$ conducted a similar study on 74 cases who had lower limb reconstruction with perforator flaps performed and noted an overall complication rate of $44 \%$. The most common complication was venous congestion (17\%) and superficial necrosis (11\%). Sixty-four percent of the patients recovered with no further treatment with $2 \%$ total flap failure and partial flap failure each. The remaining patients with complications underwent debridement and skin grafting.

With regard to the outcomes of the common individual flaps specifically, Robotti et al ${ }^{44}$ presented 24 PTA perforator flaps for lower limb reconstruction. All 24 flaps survived and did not require secondary debulking or further surgery. There were two cases $(8.3 \%)$ of distal flap necrosis which were managed conservatively. There was mention of a transitory "pin cushioning" of the flaps which resolved within a few months. Lu et $\mathrm{al}^{45}$ reviewed 18 PA perforator flaps, 11 which were propeller flaps, and the remainder comprised of peninsular flaps (perforator plus) and advancement flaps. Complications were witnessed almost exclusively from the propeller flaps with venous congestion in four cases (22\%) and flap tip congestion in one case (5.6\%). There was partial flap loss in one case (5.6\%) which required additional skin grafting. Given the relatively lower numbers of use of the remaining perforator flaps reported, it would be difficult to analyze the outcomes of the remaining types of flaps.

In contrast, the overall flap failure rates for free flaps can range from 4 to $19 \%$. The overall complication rates for free flaps are comparable to perforator flaps, ranging from 16 to $38 \% .^{2}$ In all studies, there were no statistically significant correlation between any of the complications with regard to age, gender, etiology, size of defect, type of flap, rotational arc, smoking, diabetes, and peripheral vascular diseases. It would appear that venous congestion and partial flap loss are the two most common complications encountered for perforator flaps across all studies. Despite the complications, a vast majority of perforator flaps were noted to survive, and secondary surgery is rarely required.

\section{Conclusion}

Lower limb perforator flaps are versatile and can be depended upon in the reconstruction of wounds in the distal leg and foot. While the perforators from the PTA and PA are the main workhorses for wound coverage, one must be cognizant of the multiple other perforator flaps that have been described. Moreover, the use of freestyle perforator flaps may also be considered. Quicker to perform and with less donor site morbidity, perforator flaps are an alternative option to free flaps in selected cases.

\section{Conflict of Interest}

None declared.

\section{References}

1 Soltanian H, Garcia RM, Hollenbeck ST. Current concepts in lower extremity reconstruction. Plast Reconstr Surg 2015;136(6):815e-829e

2 GirP,Cheng A,OniG, Mojallal A,Saint-Cyr M.Pedicled-perforator (propeller) flaps in lower extremity defects: a systematic review. J Reconstr Microsurg 2012;28(9):595-601

3 Georgescu AV. Propeller perforator flaps in distal lower leg: evolution and clinical applications. Arch Plast Surg 2012;39(2):94-105

4 Yoshimura M, Shimada T, Imura S, Shimamura K, Yamauchi S. Peroneal island flap for skin defects in the lower extremity. J Bone Joint Surg Am 1985;67(6):935-941

5 Kroll SS, Rosenfield L. Perforator-based flaps for low posterior midline defects. Plast Reconstr Surg 1988;81(4):561-566

6 Koshima I, Soeda S. Inferior epigastric artery skin flaps without rectus abdominis muscle. Br J Plast Surg 1989;42(6):645-648

7 Hyakusoku H, Yamamoto T, Fumiiri M. The propeller flap method. Br J Plast Surg 1991;44(1):53-54

8 Hallock GG. The propeller flap version of the adductor muscle perforator flap for coverage of ischial or trochanteric pressure sores. Ann Plast Surg 2006;56:540-542

9 Blondeel PN, Van Landuyt KH, Monstrey SJ, et al. The "Gent" consensus on perforator flap terminology: preliminary definitions. Plast Reconstr Surg 2003;112:1378-1383, quiz 1383, 1516, discussion 1384-1387

10 Pignatti M, Ogawa R, Hallock GG, et al. The “Tokyo" consensus on propeller flaps. Plast Reconstr Surg 2011;127(2):716-722

11 Mathes SJ, Nahai F. Reconstructive Surgery: Principles, Anatomy, \& Technique. St Louis: Quality Medical Publishing; 1997

12 Taylor GI, Palmer JH. The vascular territories (angiosomes) of the body: experimental study and clinical applications. Br J Plast Surg 1987;40(2):113-141

13 Saint-Cyr M, Wong C, Schaverien M, Mojallal A, Rohrich RJ. The perforasome theory: vascular anatomy and clinical implications. Plast Reconstr Surg 2009;124(5):1529-1544

14 Hamilton WJ. (1976) Textbook of Human Anatomy. London, UK: Palgrave Macmillan UK. DOI 10.1007/978-1-34906486-1

15 Meissner MH. Lower extremity venous anatomy. Semin Intervent Radiol 2005;22(3):147-156

16 Attinger CE, Evans KK, Bulan E, Blume P, Cooper P. Angiosomes of the foot and ankle and clinical implications for limb salvage: reconstruction, incisions, and revascularization. Plast Reconstr Surg 2006;117(7, Suppl):261S-293S

17 Geddes CR, Tang M, Yang D, et al Anatomy of the integument of the lower extremity. In: Blondeel PN, Morris SF, Hallock GG, et al., eds. Perforator Flaps: Anatomy, Technique \& Clinical Applications. St. Louis: Quality Medical Publishing, Inc.; 2006:541-578

18 Schaverien M, Saint-Cyr M. Perforators of the lower leg: analysis of perforator locations and clinical application for pedicled perforator flaps. Plast Reconstr Surg 2008; 122(1):161-170

19 Koshima I, Itoh S, Nanba Y, Tsutsui T, Takahashi Y. Medial and lateral malleolar perforator flaps for repair of defects around the ankle. Ann Plast Surg 2003;51(6):579-583

20 Winaikosol K, Punyavong P, Jenwitheesuk K, Surakunprapha P, ChowchuenB.Dorsalispedisperforatorflap:cadavericAnatomical Study. J Med Assoc Thai 2016;99(Suppl 5):S137-S140

21 Russo A, Delia G, Casoli V, Colonna MR, Stagno d'Alcontres F. Dorsalis Pedis Adipofascial Perforator flap for great toe reconstruction: anatomical study and clinical applications. J Plast Reconstr Aesthet Surg 2014;67(4):550-554

22 Yeo CJ, Sebastin SJ, Ho SY, Tay SC, Puhaindran ME, Lim AY. The dorsal metatarsal artery perforator flap. Ann Plast Surg 2014;73(4):441-444 
23 El-Sabbagh AH. Skin perforator flaps: an algorithm for leg reconstruction. J Reconstr Microsurg 2011;27(9):511-523

24 Quaba O, Quaba A. Pedicled perforator flaps for the lower limb. Semin Plast Surg 2006;20(2):103-111

25 Yang D, Yang JF, Morris SF, Tang M, Nie C. Medial plantar artery perforator flap for soft-tissue reconstruction of the heel. Ann Plast Surg 2011;67(3):294-298

26 Masquelet AC, Beveridge J, Romana C, Gerber C. The lateral supramalleolar flap. Plast Reconstr Surg 1988;81(1):74-81

27 Hansen T, Wikström J, Johansson LO, Lind L, Ahlström H. The prevalence and quantification of atherosclerosis in an elderly population assessed by whole-body magnetic resonance angiography. Arterioscler Thromb Vasc Biol 2007;27(3):649-654

28 Wallace CG, Kao HK, Jeng SF, Wei FC. Free-style flaps: a further step forward for perforator flap surgery. Plast Reconstr Surg 2009;124(6 Suppl):e419-e426

29 Ono S, Sebastin SJ, Yazaki N, Hyakusoku H, Chung KC. Clinical applications of perforator-based propeller flaps in upper limb soft tissue reconstruction.J Hand Surg Am 2011;36(5):853-863

30 Lee BT, Lin SJ, Bar-Meir ED, Borud LJ, Upton J. Pedicled perforator flaps: a new principle in reconstructive surgery. Plast Reconstr Surg 2010;125(1):201-208

31 Mehrotra S. Perforator-plus flaps: a new concept in traditional flap design. Plast Reconstr Surg 2007;119(2):590-598

32 Yasir M, Wani AH, Zargar HR. Perforator flaps for reconstruction of lower limb defects. World J Plast Surg 2017;6(1):74-81

33 Wang C, Yang S, Zhang J, et al. An overview of pre-expanded perforator flaps: part 1, current concepts. Clin Plast Surg 2017;44(1):1-11

34 Moscatiello F, Masià J, Carrera A, Clavero JA, Larrañaga JR, Pons G. The 'propeller' distal anteromedial thigh perforator flap. Anatomic study and clinical applications. J Plast Reconstr Aesthet Surg 2007;60(12):1323-1330

35 Ono S, Ogawa R, Eura S, Takami Y, Hyakusoku H. Perforator-supercharged perforator-based propeller flaps. Plast Reconstr Surg 2012;129(5):875e-877e
36 Horta R, Valença-Filipe R, Nascimento R, Monteiro D, Silva A, Amarante JM. Perforator-based propeller flap with venous axial supercharging for reconstruction of a leg defect. Injury 2014;45(12):2118-2119

37 Chiu DT, Hu G, Wu J, Rhee S, Rogers L, Gorlick N. Extended rat-ear flap model: a new rodent model for studying the effects of vessel supercharging on flap viability. J Reconstr Microsurg 2002;18(6):503-508

38 Dhar SC, Taylor GI. The delay phenomenon: the story unfolds. Plast Reconstr Surg 1999;104(7):2079-2091

39 Morris SF, Taylor GI. The time sequence of the delay phenomenon: when is a surgical delay effective? An experimental study. Plast Reconstr Surg 1995;95(3):526-533

40 Acartürk TO, Dinçyürek H, Dağlıoğlu K. Delay by staged elevation of flaps and importance of inclusion of the perforator artery. J Hand Microsurg 2015;7(1):1-5

41 Christiano JG, Rosson GD. Clinical experience with the delay phenomenon in autologous breast reconstruction with the deep inferior epigastric artery perforator flap. Microsurgery 2010;30(7):526-531

42 Bektas G, Ozkan O, Cinpolat A, Bassorgun IC, Ciftcioglu MA, Ozkan O. Comparing the effects of pedicle torsion on axial or perforator flaps; improving the perforator flap resistance to pedicle torsion with delay phenomenon. J Reconstr Microsurg 2014;30(8):531-538

43 Innocenti M, Menichini G, Baldrighi C, Delcroix L, Vignini L, Tos P.Are there risk factors for complications of perforator-based propeller flaps for lower-extremity reconstruction? Clin Orthop Relat Res 2014;472(7):2276-2286

44 Robotti E, Carminati M, Bonfirraro PP, et al. "On demand" posterior tibial artery perforator flaps: a versatile surgical procedure for reconstruction of soft tissue defects of the leg after tumor excision. Ann Plast Surg 2010;64(2):202-209

45 Lu TC, Lin CH, Lin CH, Lin YT, Chen RF, Wei FC. Versatility of the pedicled peroneal artery perforator flaps for soft-tissue coverage of the lower leg and foot defects. J Plast Reconstr Aesthet Surg 2011;64(3):386-393 